\title{
Novel Structural Mechanism of Glutathione as a potential peptide inhibitor to the main protease (Mro): CoviD-19 treatment, Molecular docking and SAR study
}

\author{
Abderahmane LINANI ${ }^{1 *}$, Khedidja BENAROUS ${ }^{1}$, Mohamed YOUSFI ${ }^{1}$ \\ ${ }^{1}$ Fundamental sciences laboratory, Amar Telidji University, Laghouat, Algeria \\ ${ }^{*}$ Corresponding author: abde.linani@lagh-univ.dz
}

\begin{abstract}
2019-nCoV Coronavirus spread all over the world and obliged one billion people in open confinement, no treatments or vaccine have been yet found against this pandemic. The Main Protease $\left(\mathrm{M}^{\mathrm{pro}}\right)$ is an attractive drug target, because it is the essential protein for the virus invasion. This study aims to test in silico the effect of five vitamins and a natural antioxidant against $\mathrm{M}^{\mathrm{pro}}$, using molecular docking study, with Autodock Vina and Discovery Studio visualizer softwares. The used inhibitors were chosen based on their beneficial properties such as Tocopherol (vitamin E), Thiamine (vitamin B1), Pantothenic acid (vitamin B5), Pyridoxine (vitamin B6), Biotin (vitamin B7), and Glutathione (GSH), the best inhibitor pose was chosen based on the repetition ratio (RR) and the minimum affinity energy value (MEV). The results show that Glutathione is the best inhibitor model among the other tested vitamins in the active site of $\mathrm{M}^{\text {pro }}$ with a RR value of $94 \%$ and MEV of - $5.5 \mathrm{kcal} / \mathrm{mol}$, the compatibility of Glutathione structure inside the binding pocket as a tripeptide model found to be similar to the native ligand of $\mathrm{M}^{\text {pro }}$. Moreover, Thiamine, Biotin, and Tocopherol are saved as satisfied inhibitors to $\mathrm{M}^{\text {pro }}$, Pyridoxine was the weakest inhibitor. Depending on this result, we recommend the use of Glutathione and vitamin B family as a supportive strategy for the treatment of COVID-19.
\end{abstract}

Keywords: COVID-19, Main Protease, Molecular docking, Glutathione, Thiamine. 


\section{Introduction}

The novel coronavirus disease (abbreviated "COVID-19 or nCoV-19") is the pandemic of the $21^{\text {st }}$ century caused by a new mutate family of viruses belongs to clade $\beta$ of the genus Betacoronavirus [1], infects the lungs and causes the severe acute respiratory syndrome (SARS) [2]. Recorded the first time in Wuhan, China in December 2019 [3]. It spreads quickly through any near contact with an infected person or surface [4]. It causes within the first contact, fever $\left(37.5^{\circ} \mathrm{C}\right.$ or higher), cough, dry cough, and tiredness. After a period of incubation of less than one to fourteen days [5], the virus can be very serious and even fatal for older people or those having chronic diseases like diabetes, cardiovascular, and cancer. It can be recovered without needing any treatment for most normal people $[5,6]$. When the virus enters the body, it rapidly infects the respiratory system and causes illness which can lead to breathing difficulties, in severe cases needs emergency care for breathing. The lung appears to be the most vulnerable target organ [7] because of the vast surface area of the lung, which makes the lung highly susceptible to inhaled viruses. The lining of the respiratory tree becomes injured, causing inflammation, this, in turn, irritates the nerves in the lining of the airway [8].

There is currently no vaccine to prevent coronavirus disease (COVID-19). Today the situation is on the rise, more than 2,392,166 coronavirus cases are confirmed with 164,391 deaths and 614,756 recovered in 185 countries. United States of America, Spain, Italy, and Germany are the most touched countries in the world [9]. Earlier in the year 2020, the World Health Organization (WHO) announced an emergency state due to non-treatment available and obliged people to stay in their homes and apply confinement for months in an attempt to containment the pandemic [10].

The present in silico study focused on the main protease $\left(\mathrm{M}^{\mathrm{pro}}\right)$ which is an essential component for the proteolytic maturation of the virus and has been proved as a potential target viral protein $[11,12]$. We have done molecular docking study by Autodock vina and Discovery Studio 
Visualizer (DSV) packages. we used five vitamins and known antioxidant as potential inhibitors against $\mathrm{M}^{\mathrm{pro}}$, according to their properties in boosting immunity and maintaining the neurological system like in HIV Disease such as vitamins B Group including vitamin B1, B5, B6, and B7 [13, 14], in cardiovascular diseases vitamin $\mathbf{E}$ was proved effective [15], and Glutathione as an agent to reduce oxidative stress [16-18]. 


\section{Materials and Methods}

\subsection{Receptor and ligand data collection}

The crystal structure of the Main Protease (Mpro) (pdb ID: 6lu7) was obtained from the Protein Data Bank (PDB) [11] and used as a receptor (fig 1). The inhibitors used in the present study were Thiamine (vitamin B1), Pantothenic acid (vitamin B5), Pyridoxine (vitamin B6), Biotin (vitamin B7), a_tocopherol (vitamin E), and Glutathione (GSH) (fig 2). The threedimensional structure (3D) of the six inhibitors were obtained from PubChem database in .sdf format [19].

\subsection{Molecular docking settings}

The Molecular Docking (MD) was run using Autodock vina program [20] in eight CPU station used to perform MD and set to given full flexibility to the ligand (inhibitor), the MD was preformed using blind docking. The MD consists of three main steps the first (one); consist of removing the ligands, heteroatoms, co-crystallized solvent and the unnecessary water molecules except the involved in the active site defined by Autodock vina, in this case three water molecules was kept inside the binding pocket of $\mathrm{M}^{\text {pro }}$. The second step (two), consists of adding hydrogens and partial charges using Autodock Tools (ADT) (version 1.5.4). The third step (three), consists of setting the grid box (GB) center and size of the binding pocket by the grid coordinates $x, y$ and $z$. The chosen setting for the GB center and size were $(x=-26.28, y=$ 12.60, and $\mathrm{z}=58.96)$, and $(\mathrm{x}=52, \mathrm{y}=68$, and $\mathrm{z}=68)$, respectively, with one $\AA$ separated grid points positioned in the middle of the protein using ADT. The default settings were used, except that the number of output conformations was set to one. The number of docking conformations was set at 50 poses. The "random seed" is random. The best poses were chosen based on their minimum binding energy values $(\mathrm{MEV})$ in $\mathrm{kcal} / \mathrm{mol}$ and the ratio of the most repeated poses (RR) in percent (\%) besides polar hydrogens, and hydrophobics interactions inside the binding 
pocket of $\mathrm{M}^{\text {pro }}$. The obtained MD results were analyzed using Discovery Studio Visualizer DSV), v 4.0 [21][22].

\section{Results and discussion}

The results show that the SARS-CoV-2 $\mathrm{M}^{\text {pro }}$ is a medium-size proteases protein with two chains named A: composed of 306 residues and C: composed of 6 residues represent the peptide inhibitor named: n-[(5-methylisoxazol-3-yl)carbonyl]alanyl-1-valyl-n 1 -((1r,2z)-4 (benzyloxy)-4-oxo-1([(3r)-2-oxopyrrolidin-3 yl]methyl)but-2-enyl)-l-leucinamide [11] with total residue count of 312 amino acids and a molecular weight of $34 \mathrm{KDa}$ (fig 1). Based on the Repetition Ratio (RR) and the Minimum Energy Value (MEV) inside the binding pocket of $\mathrm{M}^{\text {pro }}$, the results show that Glutathione is the best inhibitor among the other five vitamins with RR of $94 \%$ and with MEV of $-5.5 \mathrm{Kcal} / \mathrm{mol}$, in the other side Pyridoxine reported as the weakest inhibitor model with RR of $4 \%$ and $\mathrm{MEV}$ of $-4.8 \mathrm{Kcal} / \mathrm{mol}$. All results are summarized in table 1.

To better understand the mechanisms related to our inhibitors, we focus on the binding site analysis of the $\mathrm{M}^{\text {pro }}$ active site, from a structural view, the active site forms an I shape and located in a deep tunnel within the enzyme in the upper side of chain A and formed by the Binding Pockets (BP) amino acids. We defined the BP depending on the native inhibitor captured in an active catalysis moment. The BP amino acids identified were HIS41, CYS44, MET49, PRO52, TYR54, TYR118, PHE140, LEU141, ASN142, GLY143, SER144, CYS145, HIS163, HIS164, MET165, GLU166, LEU167, PRO168, HIS172, PHE181, VAL186, ASP187, ARG188, GLN189, THR190, ALA191, GLN192. We propose that all the inhibitors tested in this study bind covalently to the residue CYS145 or LEU141 in the Mro active site through the determined interatomic distances. That's elucidating the high reactivity of thiol group and the importance of these two amino acids in the active site. To study the interactions formed with our inhibitors, we defined the Catalytic Amino Acids (CAA) in every inhibitor 
model inside the active site of $\mathrm{M}^{\text {pro }}$, the $\mathrm{CAA}$ recorded toward the vitamin B family (fig 2) including Thiamine (vitamin B1), Pantothenic acid (vitamin B5), Biotin (vitamin B7), and Pyridoxine (vitamins B6) were (HIS41, MET49, TYR54, LEU141, ASN142, CYS145, HIS163, HIS164, MET165, GLU166, HIS172, ASP187, LEU141, GLY143, SER144), (LEU141, HIS163, HIS164, ASP187), (LEU141, GLY143, SER144, CYS145), and (CYS145), respectively. We defined that the nucleophilic atoms reacting are the hydroxyl functions of the CAA represented by the oxygen atom as the most negatively charged atom toward the vitamin B family hydrogens, which presented as the electrophilic atoms, the CAA responsible for the nucleophilic attack is ASN142 with $1.95 \AA$, CYS145 with $3.71 \AA$, for thiamine, pyridoxine respectively, and HIS164 for both biotin with $1.80 \AA$, and with pantothenic acid with $1.83 \AA$. All the interactions saved were conventional hydrogen bonds type. The Thiamine (fig 3) was saved as the most preferred inhibitor in the active site of $\mathrm{M}^{\text {pro }}$, among the other vitamin $\mathrm{B}$ family according to the RR and MEV values (table 1). We explain that by the structure flexibility, shape, and various chemical function properties, thus, assure its reactivity and stability which explain the high affinity to $\mathrm{M}^{\text {pro }}$ active site stabilized by 14 interaction such as, conventional hydrogen bond, carbon-hydrogen bond, and $\pi$-Sulfur bond, this interaction were saved in all obtained confirmations, and the preferred bonds were saved in both sides of aminopyrimidine and thiazolium ring linked by a methylene bridge with ASN142, CYS145, and TYR54.

The second-best inhibitor model to $\mathrm{M}^{\text {pro }}$ was the Biotin (fig 3) with lower RR and MEV comparing to Thiamine (table 1), this is resulting from the heterobicyclic form that consists of 2-oxohexahydro-1H-thieno[3,4-d]imidazole having a valeric acid substituent attached to the tetrahydrothiophene ring which minimizes the chances of flexibility inside the active site of $\mathrm{M}^{\text {pro }}$ and that was confirmed by the recorded interactions (table1) comparing to the thiamine. All the interactions bind to the lactone group attached to the 2-oxohexahydro- $1 \mathrm{H}$-thieno[3,4d]imidazole ring, which is explained by the electronegative filed powered by the oxygen atom 
as the greatest localized negative charge in the biotin. Thus, the perfect hydrogen bond in all the inhibitors was saved with HIS164, at atomic level, this amino acid could be very important in stabilizing the biotin in the active site.

The third best inhibitor model to $\mathrm{M}^{\text {pro }}$ was the Pantothenic acid (fig 3) with lower RR comparing to thiamine and biotin, however, Pantothenic acid shares the same MEV with biotin, and also the same hydrogen bond was saved with HIS164 with a length of $1.83 \AA$. In the other side, the number of interactions saved was lower comparing to the biotin, resulting in his lower affinity to $\mathrm{M}^{\text {pro }}$ when reacting alone, that explains the importance of a potential association between the biotin and the pantothenic acid, and that could be important in the inhibition mechanisms against $\mathbf{M}^{\text {pro }}$.

The last ranked inhibitor was the Pyridoxine (fig 4) as the weakest inhibitor among the vitamin B family and all tested inhibitors in this study with RR of $4 \%$ and MEV of - $4.8 \mathrm{kcal} / \mathrm{mol}$ (table 1), we recorded only one interaction with CYS145 type hydrophobic, this interaction elucidate the environment between Pyridoxine functional groups and BP amino acids which have a very little affinity, the interacting groups will be positioned in a manner to have the smallest contact surface with the active site.

The CAA recorded in Tocopherols (fig 4) were HIS41, MET49, CYS145, HIS163, MET165, PRO168, ARG188, THR190, and GLN192, the nucleophilic atom reacting was in favor of the ketone function side of ARG188 and the hydroxyl function of the tocopherols represented by the hydrogen as the electrophilic atom, only one hydrogen bond was recorded in this context and that clarifies the native structure of the ARG since the other side of it ends with a guanidinium group which enables the formation of hydrogen bonds due to the delocalization of the positive charge of the nitrogen atom in the ARG bone structure. The RR of tocopherols recorded in table 1 was very low compared with his MEV as the greatest value saved among all other inhibitors, and that is due to his high affinity with other sites since the most saved 
interactions were a hydrophobic type, that minimizes the chances of getting the exact conformation in the catalytic site of the $\mathrm{M}^{\text {pro }}$.

The best inhibitor model to $\mathrm{M}^{\text {pro }}$ active site was the Glutathione or $\boldsymbol{\gamma}$-L-glutamyl-L-cysteinylglycine (fig 3), with the best saved RR and MEV (table 1). Where the CAA recorded were HIS41, LEU141, GLY143, SER144, CYS145, GLU166, ARG188, and GLN189, according to our results, Glutathione present the highest affinity to $\mathrm{M}^{\text {pro }}$, this affinity is confirmed by various elements such as interactions type, stereochemical properties, functional groups, and compatibility with the active site volume. The Glutathione is located deeply in the active site tunnel. All the internal interactions were conventional hydrogen bond type, this assures its flexibility and stability since it formed by triple amino acids (cysteine, glutamic acid, and glycine) attached via peptide linkage and already presented in the active site which increase the reactivity and effectiveness, this factor favorize covalently the fixation of Glutathione. We propose a mechanism action of the Glutathione inside the active site of $\mathrm{M}^{\text {pro }}$ depending on the greatest localized negative charge as indicated by the most intense red color (fig 5) and the proton being transferred has the most intense positive charge character indicated by the most intense blue color (fig 5) and the best hydrogen bond saved with LEU141. The 4-steps mechanism proposed in fig 5 elucidate the formation of glutathione and leucine complex. In step1, the oxygen atom of LEU141 is the electron source and the hydroxide atom of the glutathione is the electron sink, to avoid overfilling the valence of the hydrogen atom the hydroxide bond must be broken to form the glutathione ion, this ion is often stabilized by resonance delocalization. In step 2 , the $\pi$ bond will transfer as indicated by red arrow (fig 5) to satisfy the valence in the oxygen atom of LEU141. In step 3, we obtained satisfied oxygen atom and a positive charge carbon atom with only three bonds, which lead us to step 4, ester linkage bond will be formed to stabilizing the new complex consequently, blocking the active site of $\mathrm{M}^{\text {pro }}$. 


\section{Conclusion}

Through this work, we presented the Glutathione, vitamin B family, and vitamin E as a potential inhibitor to the main protease of the novel coronavirus which can reduce the invasion of the virus. Clearly, the suggested treatment strategy help enhance and improve immunity system and block the main proteases, Glutathione used as treatment in many diseases such as Pulmonary disease, asthma, and acute respiratory distress syndrome, in immune diseases like HIV, and liver disease. The origin peptide structure of the glutathione gives him the advantageous among other inhibitors, according to our study, we recommend highly the use of the Glutathione as a double beneficial effects for preventive action and in the other side as an effective treatment besides anti-symptomatic viral drugs in case of a severe virus invasion. The consumption of glutathione and vitamin B family daily as a supplement can be a solution to limit the virus transmission. 


\section{References}

1. Wu F, Zhao S, Yu B, Chen YM, Wang W, Song ZG, Hu Y, Tao ZW, Tian JH, Pei YY et al: A new coronavirus associated with human respiratory disease in China. Nature 2020, 579(7798):265-269.

2. Poutanen SM, Low DE, Henry B, Finkelstein S, Rose D, Green K, Tellier R, Draker R, Adachi D, Ayers M: Identification of severe acute respiratory syndrome in Canada. New England Journal of Medicine 2003, 348(20):1995-2005.

3. Guan WJ, Ni ZY, Hu Y, Liang WH, Ou CQ, He JX, Liu L, Shan H, Lei CL, Hui DSC et al: Clinical Characteristics of Coronavirus Disease 2019 in China. The New England journal of medicine 2020.

4. LeDuc JW, Barry MA: SARS, the First Pandemic of the 21st Century. Emerg Infect Dis 2004, 10(11):e26-e26.

5. Guan W-j, Ni Z-y, Hu Y, Liang W-h, Ou C-q, He J-x, Liu L, Shan H, Lei C-1, Hui DSC et al: Clinical Characteristics of Coronavirus Disease 2019 in China. New England Journal of Medicine 2020.

6. Chen N, Zhou M, Dong X, Qu J, Gong F, Han Y, Qiu Y, Wang J, Liu Y, Wei Y et al: Epidemiological and clinical characteristics of 99 cases of 2019 novel coronavirus pneumonia in Wuhan, China: a descriptive study. Lancet (London, England) 2020, 395(10223):507-513.

7. Xu Z, Shi L, Wang Y, Zhang J, Huang L, Zhang C, Liu S, Zhao P, Liu H, Zhu L et al: Pathological findings of COVID-19 associated with acute respiratory distress syndrome. The Lancet Respiratory medicine 2020.

8. Ksiazek TG, Erdman D, Goldsmith CS, Zaki SR, Peret T, Emery S, Tong S, Urbani C, Comer JA, Lim W et al: A Novel Coronavirus Associated with Severe Acute Respiratory Syndrome. New England Journal of Medicine 2003, 348(20):1953-1966.

9.

10. Coronavirus disease (COVID-19) outbreak [https://www.who.int]

11. Jin Z, Du X, Xu, Y., Deng, Y., Liu, M., Zhao, Y., Zhang, B., Li, X., Zhang, L., Peng, C., Duan, Y., Yu, J., Wang, L., Yang, K., Liu, F., Jiang, R., Yang, X., You, T., Liu, X., Yang, X., Bai, F., Liu, H., Liu, X., Guddat, L., Xu, W., Xiao, G., Qin, C., Shi, Z., Jiang, H., Rao, Z., Yang, H.: Structure of Mpro from COVID-19 virus and discovery of its inhibitors: http://www.rcsb.org/structure/6LU7; 2020. 
12. Anand K, Ziebuhr J, Wadhwani P, Mesters JR, Hilgenfeld R: Coronavirus main proteinase (3CLpro) structure: basis for design of anti-SARS drugs. Science 2003, 300(5626): 1763-1767.

13. Miller LT: Vitamin B Group and the Immune System. In: Encyclopedia of Immunology (Second Edition). Edited by Delves PJ. Oxford: Elsevier; 1998: 2490-2491.

14. Dahmer S, Kligler B: Chapter 19 - HIV Disease and AIDS. In: Integrative Medicine (Fourth Edition). Edited by Rakel D: Elsevier; 2018: 180-190.e182.

15. Han J, Zhao C, Cai J, Liang Y: Comparative efficacy of vitamin supplements on prevention of major cardiovascular disease: Systematic review with network metaanalysis. Complementary Therapies in Clinical Practice 2020, 39:101142.

16. Lu SC: Glutathione synthesis. Biochim Biophys Acta 2013, 1830(5):3143-3153.

17. Pizzorno J: The path ahead: measuring oxidative stress. Integrative Med Clin J 2009, 8(3):8-10.

18. MERCuRy L: Clinical experience in decreasing mercury load. Integrative Medicine 2011, 10(4): 10 .

19. Kim S, Thiessen PA, Bolton EE, Chen J, Fu G, Gindulyte A, Han L, He J, He S, Shoemaker BA et al: PubChem Substance and Compound databases. Nucleic Acids Res 2016, 44(D1):D1202-1213.

20. Trott O, Olson AJ: AutoDock Vina: improving the speed and accuracy of docking with a new scoring function, efficient optimization, and multithreading. Journal of computational chemistry 2010, 31(2):455-461.

21. Dassault Systèmes BIOVIA: BIOVIA Workbook, Release 2017; BIOVIA Pipeline Pilot, San Diego: Dassault Systèmes. 2017.

22. Serseg T, Benarous K, Yousfi M: Hispidin and Lepidine E: two Natural Compounds and Folic acid as Potential Inhibitors of 2019-novel coronavirus Main Protease (2019-nCoVMpro), molecular docking and SAR study. Current Computer-Aided Drug Design 2020:in press. 


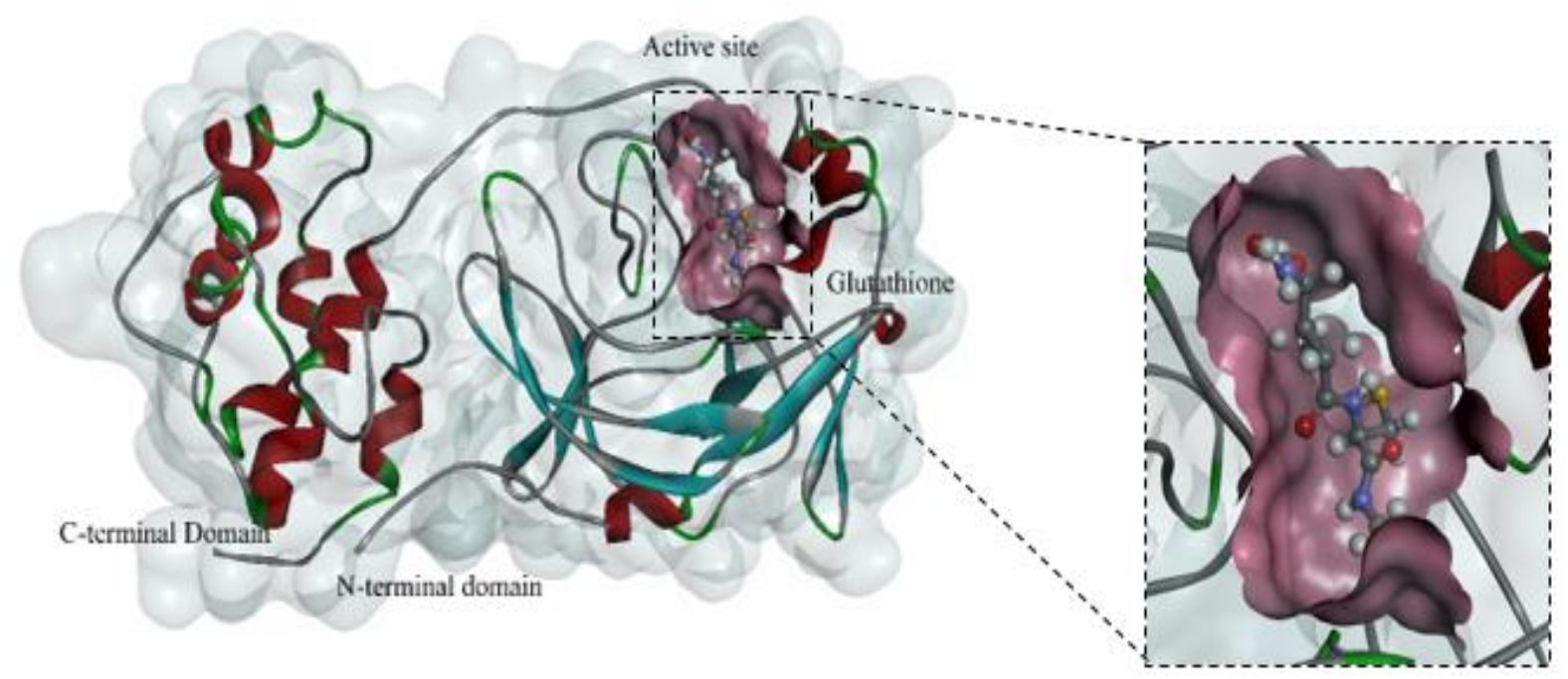

Fig 1. The 3D structure of the main protease protein (pdb ID: 6lu7) colored in bleu and zooming on the active site colored in pink and complexed with Glutathione (presented in ball and stick) 
Glutathione<smiles>NC(CCC(=O)NC(CS)C(=O)NCC(=O)O)C(=O)O</smiles>

\section{Biotin}<smiles>O=C(O)CCCC[C@@H]1SCC[C@H]1NC(=O)O</smiles>

a-tocopherol

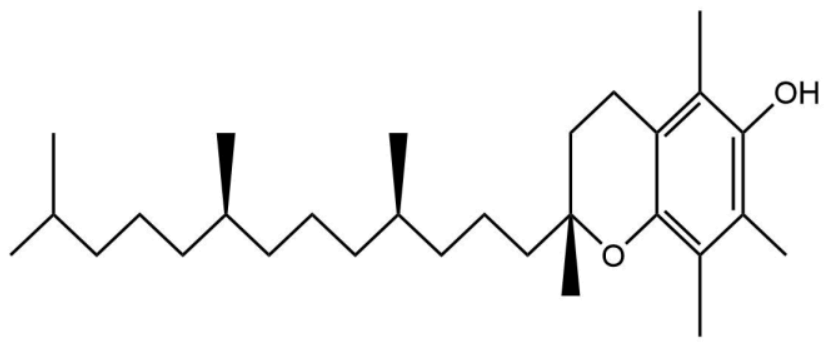

Thiamine<smiles>Cc1ncc(C[n+]2csc(CCO)c2C)c(N)n1</smiles>

Pantothenic acid<smiles>CC(C)(CO)C(O)C(=O)NCCC(=O)O</smiles>

Fig 2. The two-dimensional (2D) structure of the tested inhibitors 

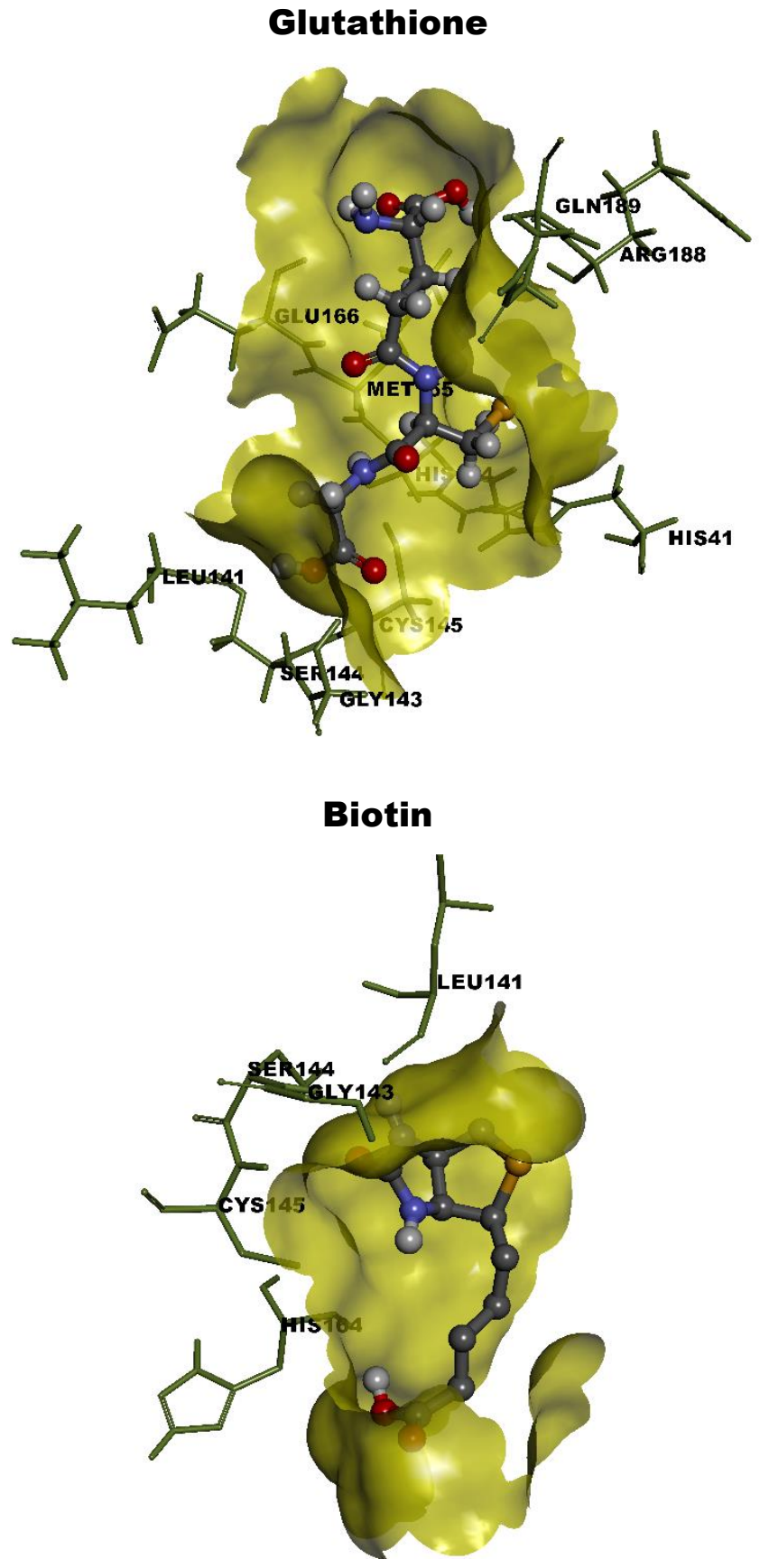

Thiamine

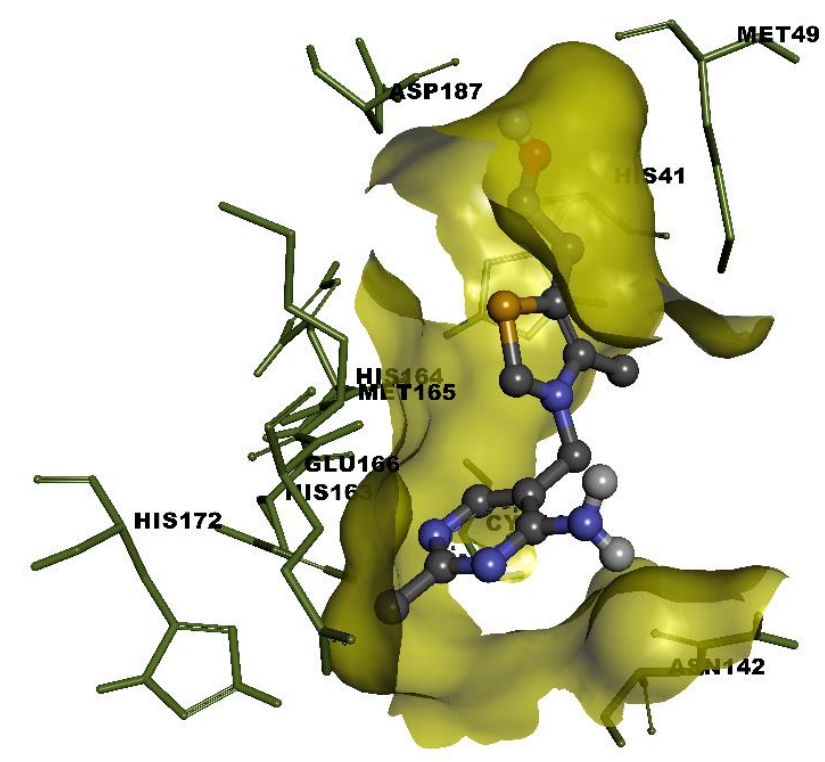

Pantothenic acid

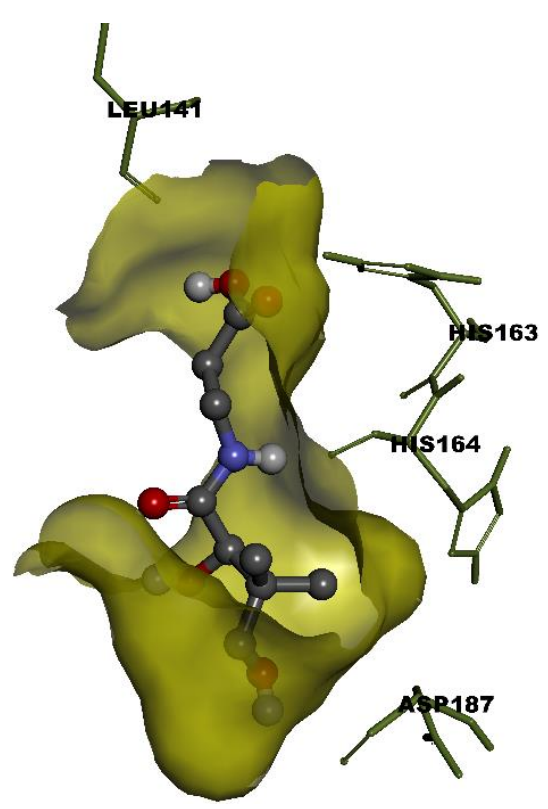

Fig 3. The best inhibitor pose captured in the active site of $\mathrm{M}^{\text {pro }}$ presented in surface and colored in yellow, inhibitors are presented in ball and stick, the catalytic amino acids are presented in stiks and colored in green 


\section{a-tocopherol}

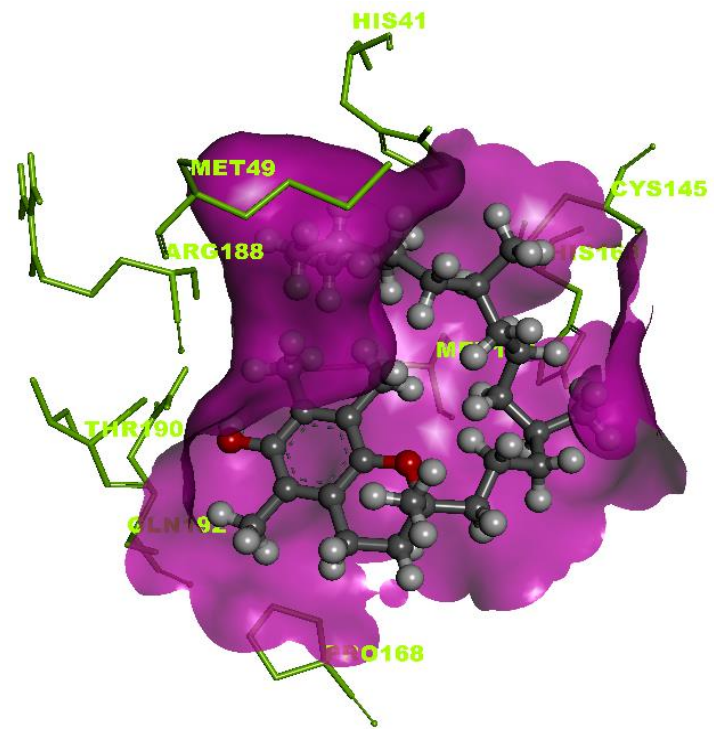

Pyridoxine

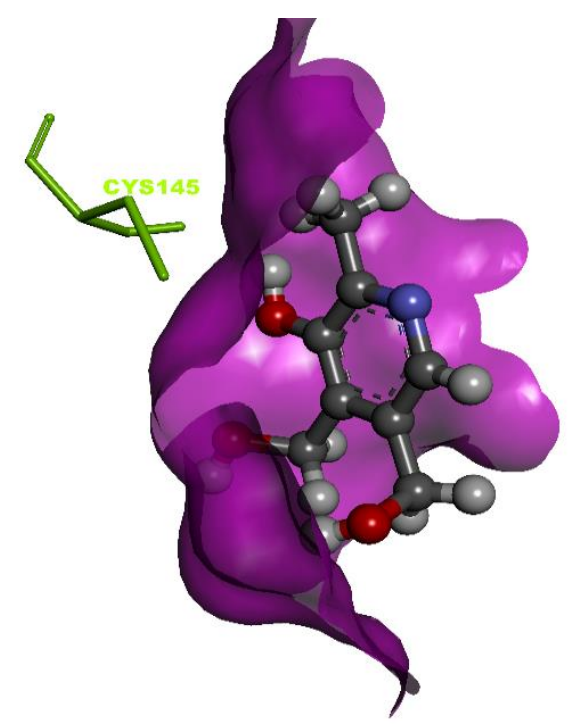

Fig 4. The weakest inhibitors pose captured in the active site of $\mathrm{M}^{\text {pro }}$ presented in surface and colored in purple, inhibitors are presented in ball and stick, the catalytic amino acids are presented in sticks and colored in green 
Chemical Formula: $\mathrm{C}_{10} \mathrm{H}_{16} \mathrm{~N}_{3} \mathrm{O}_{6} \mathrm{~S}^{-}$ Exact Mass: 306,08

Glutathione

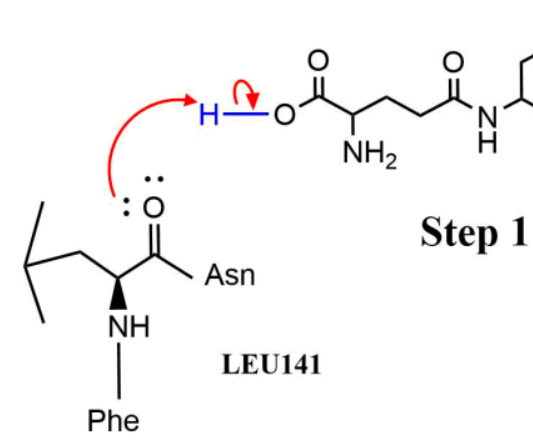

Glutathione ion<smiles>CC(C)(C)C(=O)NC(CS)C(=O)NC(=O)CCC(N)C(=O)NCC(=O)O</smiles>

Step 2<smiles>CN[C@H](CC(C)C)C1(O)C2(C(=O)OCC(=O)NC(CS)C(=O)NC(=O)CCC(N)C(=O)O)CCCC1(C(C)C)C2</smiles>

Phe<smiles>CCCCCCCC(=O)C(=O)[C@H](CC(C)C)Nc1ccccc1</smiles>

Glutathione ion<smiles>NC(CCC(=O)NC(CS)C(=O)NCC(=O)[O-])C(=O)O</smiles><smiles>CN[C@H](CC(C)C)[C@@](C)(O)C(=O)[Mg]</smiles>

Phe

LEU141

Step 4

Step 3

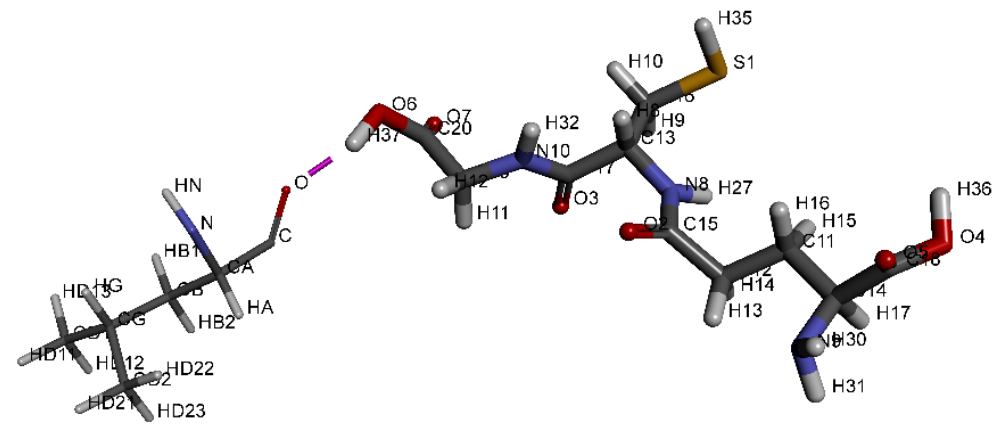

LEU141

Glutathione

Fig 5. Proposed mechanism of the glutathione with LEU141 in the active site of $\mathrm{M}^{\text {pro }}$ 
Table 1. The receptor-ligand complex interaction results

\begin{tabular}{|c|c|c|c|c|c|c|}
\hline Rank & Inhibitors & $\begin{array}{l}\mathbf{R R} \\
(\%)\end{array}$ & $\underset{\text { (kcal/mol) }}{\text { MEV }}$ & $\begin{array}{l}\text { Nucleophilic } \\
\text { residues }\end{array}$ & $\begin{array}{c}\text { Interactions } \\
\text { type }\end{array}$ & $\underset{(\AA)}{\text { Length }}$ \\
\hline 3 & $\begin{array}{c}\text { Biotin } \\
\left(\text { vit } \mathrm{B}_{7}\right) \\
\left(\mathbf{C}_{\mathbf{1 0}} \mathbf{H}_{\mathbf{1 6}} \mathbf{N}_{\mathbf{2}} \mathbf{O}_{\mathbf{3}} \mathbf{S}\right)\end{array}$ & 56 & -5.5 & HIS164 & Hydrogen Bond & 1.80 \\
\hline 1 & $\begin{array}{l}\text { Glutathione } \\
\mathrm{C}_{10} \mathrm{H}_{17} \mathrm{~N}_{3} \mathrm{O}_{6} \mathrm{~S}\end{array}$ & 94 & -5.5 & LEU141 & $\begin{array}{l}\text { Hydrogen Bond } \\
\text { Pi-Sulfur }\end{array}$ & $\begin{array}{l}1.82 \\
3.78\end{array}$ \\
\hline 4 & $\begin{array}{c}\text { Pantothenic acid } \\
\left.\text { (vit } \mathrm{B}_{5}\right) \\
\left(\mathbf{C}_{9} \mathbf{H}_{\mathbf{1 7}} \mathbf{N O}_{5)}\right.\end{array}$ & 36 & -5.5 & HIS164 & Hydrogen Bond & 1.83 \\
\hline 2 & $\begin{array}{c}\text { Thiamine } \\
\left.\text { (vit } \mathrm{B}_{1}\right) \\
\left(\mathbf{C}_{\mathbf{1 2}} \mathbf{H}_{\mathbf{1 7}} \mathbf{N}_{\mathbf{4}} \mathbf{O S}^{+}\right)\end{array}$ & 82 & -5.7 & ASN142 & $\begin{array}{l}\text { Hydrogen Bond } \\
\text { Amide-Pi Stacked } \\
\text { Alkyl } \\
\text { Pi-Sulfur }\end{array}$ & $\begin{array}{l}1.95 \\
4.70 \\
4.82 \\
4.75\end{array}$ \\
\hline 6 & $\begin{array}{l}\text { Pyridoxine } \\
\quad\left(\text { vit } \mathrm{B}_{6}\right) \\
\left(\mathrm{C}_{\mathbf{8}} \mathrm{H}_{11} \mathrm{NO}_{3}\right)\end{array}$ & 4 & -4.8 & CYS145 & $\begin{array}{l}\text { Alkyl } \\
\text { Pi-Alkyl }\end{array}$ & $\begin{array}{l}3.71 \\
4.77\end{array}$ \\
\hline 5 & $\begin{array}{l}\text { a_tocopherol } \\
(\text { vit E) } \\
\left(\mathrm{C}_{29} \mathrm{H}_{50} \mathrm{O}_{2}\right)\end{array}$ & 6 & -6.5 & ARG188 & $\begin{array}{l}\text { Hydrogen Bond } \\
\text { Alkyl } \\
\text { Pi-Alkyl }\end{array}$ & $\begin{array}{l}2.81 \\
3.95 \\
4.30\end{array}$ \\
\hline
\end{tabular}

RR: repetition ration

MEV: minimum energy value

Vit : vitamin 